\title{
Using Virtual Reality for Developing Design Communication
}

\author{
Gisli Thorsteinsson ${ }^{1}$, Tom Page ${ }^{2}$, Andrei Niculescu ${ }^{3}$ \\ ${ }^{1}$ University of Iceland, \\ v/Stakkahlid, 101, Reykjavik, Iceland \\ cdt@hi.is; \\ ${ }^{2}$ Loughborough University, \\ Loughborough, Leicestershire, LE11 3TU, UK \\ t.page@lboro.ac.uk; \\ ${ }^{3}$ Spiru Haret University, \\ 13 Ion Ghica Street, Bucharest 3, Romania \\ andreiniculescu@hotmail.com.
}

Abstract: This paper explores the possibilities of using a Virtual Reality for cooperative idea generation and then attempts to assess the relationship between a student's cooperation and the design process, learning experiences and the pedagogy employed by the teacher. The researchers based their research around the following questions:

1. How could collaborative idea generation be incorporated within the VRE?

2. How does this relate to teaching and learning within the lesson?

3. How do communications during the lesson support students' work?

Keywords: Idea generation; Virtual Reality Environment; multiple communication; cooperative idea generation; cooperative learning; user interface; remote observation, and screen captured videos.

\section{Introduction}

Conventional learning comes in a range of forms and is therefore difficult to characterise. However, learning is usually based on the idea of information provided by an instructor during lectures and printed course materials (McInnerney 2002). The primary modes of learner interaction, therefore, are learner-instructor and learnercontent (Bricken 1990), with almost no learning taking place between the students. The Virtual Reality Environment (VRE) enables multiple online communications and thus supports different forms of learning within the classroom context (Thorsteinsson \& Denton 2008).

The rapid rise of computers and networks has triggered the introduction of novel forms of communicationieducation: computermediated communications (CMC) can take many forms, but asynchronous threaded discussions give learners the time to think about problems and allowthem the opportunity to discuss possible solutions within a group (McInnerney 2002). With Virtual Reality Learning, students can access other student's responses and add to them over time (Thorsteinsson \& Denton 2006), and actively participate in constructing new knowledge (Thorsteinsson 2002). This allows students to discuss ideas in groups and solve any problems, thus extending classroom time (McInnerney 2002).

Cooperative Learning is a teaching arrangement that refers to small, heterogeneous groups of students working together to achieve a common goal (Kagan, 1994); students work together to learn and are responsible for their team-mates' learning, in addition to their own.

Hundreds of studies (including Kagan, 1994 \& Johnson, Johnson, \& Stanne 2000) have been undertaken to measure the success of cooperative learning as an instructional method with regards to social skills and student learning and achievement across all levels, from primary grades through to college. The general consensus is that cooperative learning can and usually does result in positive student outcomes in all domains (Johnson \& Johnson 2001).

The authors observed the impact of students' communication on their joint design during their work. Students' different roles and initiative were studied, as was their ability to draw inside the Virtual Reality Environment.

A pilot study was undertaken in an Icelandic elementary school, using a Virtual Reality 
(VR) to facilitate cooperative idea generation within the context of the classroom; this technology supports online communications and enables students to develop drawings and descriptions of their solutions. The VRE was connected to the Internet, and students were able to work both online and face-to-face during the lesson. The aim was to explore the ways in which idea generation was developed in students during their work; the produced data was qualitative and analysis based on grounded theory principles and an interpretive paradigm. Three data instruments were used to enable triangulation: observation, screen captured videos and the teacher's logbook. Also, using remote observation software allowed the collection of a rich record of actual computer work activity in its natural work setting. A qualitative and inductive methodology, developed by Glaser and Strauss (1967), was used to analyse the data.

The authors firstly review the literature and introduce the pilot study. Then, he discusses the research design, the undertakings of the pilot study and the findings. Finally they analyse the outcome and draw their conclusions.

\section{Virtual Reality (VR) and Related Terms}

The term 'Virtual Reality' (VR) was initially coined by Lanier (1989). Other related terms include 'Artificial Reality' (Krueger, 1970s), 'Cyberspace' (Gibson, 1984), and, more recently, 'Virtual Worlds' and 'Virtual Environments' (1990s). Virtual Reality is used today in a variety of ways but often in a confusing manner. Originally, the term referred to 'Immersive Virtual Reality'. In immersive VR, the user becomes fully immersed in an artificial, three-dimensional world generated by a computer.

Cruz-Neira, Sandin, and DeFanti (1993) state the term Virtual Reality is better than virtual reality, as it incorporates the ability to touch, hear, and smell: to act on the environment. Virtual learning environment implies a total substitution of something synthetic for something real, whereas Virtual Reality is more suitable as a facsimile for a real or imagined environment - e.g. when using a computer screen presenting a virtual world, possibly including audio.

Virtual Reality (VR) can be described as a new communication technology that involves the human senses in new ways and allows the user to intuitively interact with data (McLellan 1996). It can further be defined as the idea of human presence in a computer-generated space (Hamit 1993, p9), or more specifically, a highly interactive, computer-based, multimedia environment in which the user becomes a participant with the computer in a 'virtually real' world “(Pantelidis 1993, p23).

According to Loeffler and Anderson (1994), there are four main elements in a virtual reality environment; it is three-dimensional, computer-generated, a simulated environment, and it is rendered in real-time, according to the behaviour of the user. VR has also been described as a communication tool, and it can be used as multi-user or single-user VR communication interface. VRs have been used for many different purposes, but the most common applications are probably games and occupational simulators. However, VRs are also used for educational training and online meetings, as in this project.

Some claim that the VR is no more than a direct addition of multimedia systems (Dede 1992), yet a VR has its own unique characteristics that might be used to improve students' understanding and learning performances. It is therefore important to identify the unique characteristics of the VR that may improve this understanding and performance in an educational context. These characteristics can then be manipulated as independent variables in experimental studies of VR.

Zeltzer (1992) has proposed a framework for thinking about the characteristics of a VR, along with three dimensions that he calls autonomy, presence, and interaction. There are also other important characteristics of VRs, such as autonomy and navigation, that are useful for understanding the application of VRs, and the following sections describe these concepts: 


\section{Different Virtual Reality Environments (VR)}

Researchers use different classifications of VRs. However, two main types of technologies exist: immersive Virtual Reality (hardware VR) and a desktop-based virtual reality environment. Desktop-based VRs are based on traditional input/output devices like monitor, mouse, keyboard, microphones and speakers, whilst immersive VRs may use simulators, data gloves or body suits, shared workbenches etc. Immersive VRs are not good tools for everyday application, due to the high cost.

Web based 'virtual tours' are an example of a commonly available desktop virtual reality. Desktop-based VRs can be structured according to technological advancement and system-inherent properties (Schwienhorst 1998), and this makes them fairly useful for Innovation Education learning purposes. The VRLE technology used in this research is a desktop-based version and provides a flexible, easy-to-use multiple-user virtual reality that allows the integration of ideation learning tools and resources in a common environment.

Immersive virtual reality environments are presented on multiple, room-size screens or through a stereoscopic, head-mounted display unit. Additional specialised equipment such as the Data Glove (worn as one would a regular glove) enables the participant to interact with the virtual environment through normal body movements. Sensors on the head unit and Data Glove track the viewer's movements during exploration and provide feedback that is used to revise the display, enabling real time, fluid interactivity. Examples of virtual reality environments are a virtual solar system that enables users to fly through space and observe objects from any angle; a virtual science experiment that simulates the growth of microorganisms under different conditions; a virtual tour of an archaeological site; and a recreation of the Constitutional Convention of 1787.

\section{VRLE Technology for Education and Training}

Many educational researchers believe VRLE technology offers benefits that can support education. The VRLE capacity to deliver computer cooperate supportive learning and constructivist-learning activities is one of its most important values. Another value is its potential to provide different forms of learning to support different types of learners, such as visually oriented learners (Page et al. 2008).. Several research projects seek to establish learning within a very general educational setting, whilst a few studies have investigated the impact of immersion on the effectiveness of VRLEs. However, most of the studies seek to observe whether a VRLE is an effective educational technology or not (Winn 1993). Some of these research projects involve short-term studies, whilst others are based on longer case studies that develop virtual worlds for schools.

VRLEs have an important role to play in education because the user's interaction in a virtual environment can represent any threedimensional world that is either real or abstract. For example, the virtual worlds may be buildings; the human body; underwater; a cruise; outer space; a museum; a crime scene, or a dinner party.

Many educators and researchers support the view that VRLEs offer opportunities to experience environments which, for reasons of time, distance, scale, and safety, would not otherwise be available to many young children, especially those with disabilities (Cromby et. al. 1995). The VRLE technology can be used to explore, create, play and learn in virtual environments such as crossing roads, talking with strangers, or emergencies. Through this technology, young children can experience places that would otherwise be impossible, impractical, or too dangerous to visit.

A VR can be used to support cooperative learning and socially oriented theories of learning, using computer technologies to support collaborative methods of instruction. Instructional design is characterised by a systematic and reflective process of applying principles of learning and instruction to develop instructional materials, activities, information resources, and evaluation (Paulsen 2003). 


\section{Concepts Generation}

Ideation, or idea generation, is a concept derived from Guilford (1950) and is used to describe the pattern of interactions that form when a person works on and produces an idea; ideation is "the formation of ideas or mental images of things not present to the senses' (The Oxford Dictionary, 2006). The Webster Dictionary (http:www.webster.com) defines ideation as 'the faculty or capacity of the mind for forming ideas; the exercise of this capacity; the act of the mind by which objects of sense are apprehended and retained as objects of thought'.

Santanen et al 2004 (p23) stated that 'ideation activities are fundamental to the process of creativity'. However, reflection on the definitions in the previous paragraphs shows that the process of idea generation clearly requires ideation skills. In an idea generation session, one or more people work to generate solutions to a problem or opportunity, intending to generate solutions that might otherwise go unrealised.

Osborn (1963) recommended that idea generation be seen as a separate activity from idea evaluation; this approach resulted in an increased emphasis on idea generation, which tended to overshadow idea evaluation (Smith 2001). Maier (1963) concluded that this segregation and increased focus would ultimately improve the quality of problem solving. This approach is consistent with Demerest's (1997) knowledge management approach, where knowledge creation is recognised as a key separate activity, yet supportive of idea generation. These events occur prior to the phase of knowledge embodiment in organisational groups, where filtering rules are applied similar to those of idea evaluation. Miller and Morris (1999) argue that idea generation based on an expansive view of knowledge creation is essentially the grouping and integration of ideas from many sources of accepted knowledge, prior to the viewing of those ideas.

\section{Cooperative Learning}

Cooperative learning is generally defined as a teaching arrangement in which small, heterogeneous groups of students work together to achieve a common goal (Kagan1994 \& Ravitch 2007), with each student having a specific responsibility within the group. Advocates believe that cooperative learning enables students to acquire both knowledge and social skills, and that those students try harder because they are members of a team; they also contend that students have more opportunities to ask questions and clarify confusions than they do in a wholeclass setting (Kagan 1994 \& Slavin 1991). Critics complain that group work wastes time and that high-performing student's end up doing most of the work (Ravitch (2007).

Millis (1996) outlines five characteristics associated with cooperative learning:

- Students work together in small groups of 2-5

- Students work together on common tasks or learning activities that are best handled through groupwork

- Students use cooperative, pro-social behaviour to accomplish their common tasks or learning activities

- Students are positively interdependent and activities are structured so that students need each other to accomplish their common tasks or learning activities

- Students are individually accountable or responsible for their work or learning.

In cooperative learning groups, students encourage and support each other, assume responsibility for their own and each other's learning employ group-related social skills, and evaluate the group's progress (McInnerney 2002). The basic elements are positive interdependence, equal opportunities, and individual accountability (Kagan1994 \& Ravitch 2007). Human beings are social creatures by nature, and thus cooperative learning groups should be used more within schools as a teaching method (Ravitch 2007).

Cooperative learning as a teaching method began to be developed during the 1960s and was evaluated in a wide variety of teaching contexts (Ravitch 2007). Thorough research into cooperative learning found that cooperative learning strategies improve the achievement of students and their interpersonal relationships (Slavin 1991). 
Johnson, Johnson, \& Stanne (2000) stated that cooperative learning strategies are widely used because they are based on theory validated by research, and almost any teacher can find a way to use cooperative learning methods that are consistent with personal philosophies. Factors contributing to the achievement of cooperative learning are group goals and individual accountability; providing students with an incentive to help and encourage each other increases the likelihood that all group members will learn. In addition to individual grades and evaluations, there is strong evidence that group grades and team rewards are the most successful motivational tools (Page et al. 2009). Some educationalists, however, argue that group grades and team rewards allow some students to 'free ride', which means they do not participate to the fullest extent of their abilities (Joyce 1999 and Cohen 1998). It has also been argued that group grading deemphasises the importance of hard-work, personal ability, and perseverance (Kagan 1995). Cooperative learning enhances social interaction, which is essential to meet the needs of at-risk students (Slavin, Karweit, \& Madden 1989; Johnson 1998). In cooperative learning groups, students learn how to interact with their peers, thus increasing their participation within the school community (McInnerney 2002). Positive interactions do not always occur naturally, and social skills instruction must precede and run alongside the cooperative learning method. Social skills include communicating, building and maintaining trust, providing guidance, and handling conflict (Goodwin 1999).

\section{The Virtual Reality Used in the Study}

The Virtual Reality used was part of an Icelandic Virtual Reality Learning System that included both a managed learning environment (MLE) and Virtual Reality (VLE) (Thorsteinsson et al. 2005). The VRE element was developed as a communication tool to enable cooperative idea generation; it allows participants to utilise synchronous virtual communication with sound, pictures, and movements. It also offers the possibility of using CAD for communicating ideas in the form of drawings and the formation of $3 \mathrm{D}$ objects Thorsteinsson \& Denton 2006). The use of the VRE element was established, incorporating security requirements; it was possible to enter the VRE from inside a personal workshop after the user had passed all the security requirements (Thorsteinsson et al. 2005). When the user entered the VRE, they could choose from a range of avatars (see Figure 1), representing both adults and children.

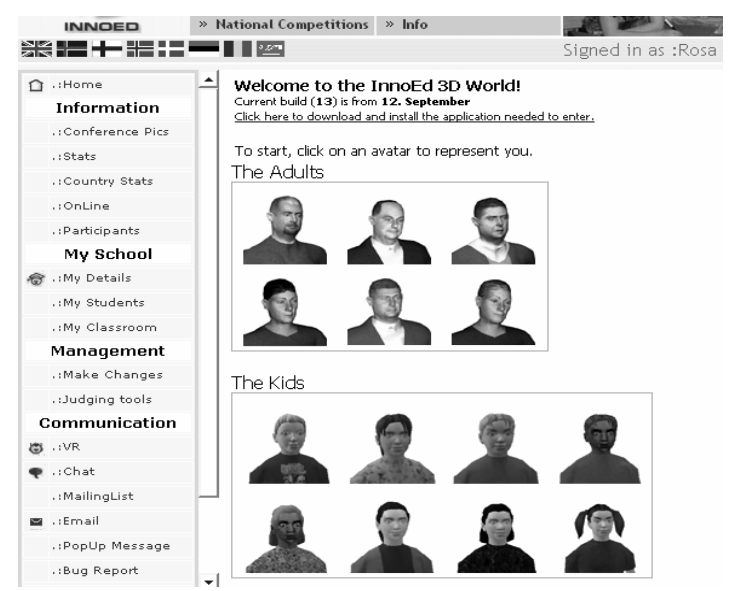

Figure 1. The available avatar range.

The VRE was designed in the form of a house, with many rooms and a garden. The students could walk about and communicate by using voice over IP, or by sending text that appeared on the screen; they could also interact and communicate using their avatar's body language. Each room in the VRE had big screens for playing videos, browsing the Internet, showing Power Point presentations, along with whiteboards that enabled the participants to draw together (Thorsteinsson \& Denton 2006).

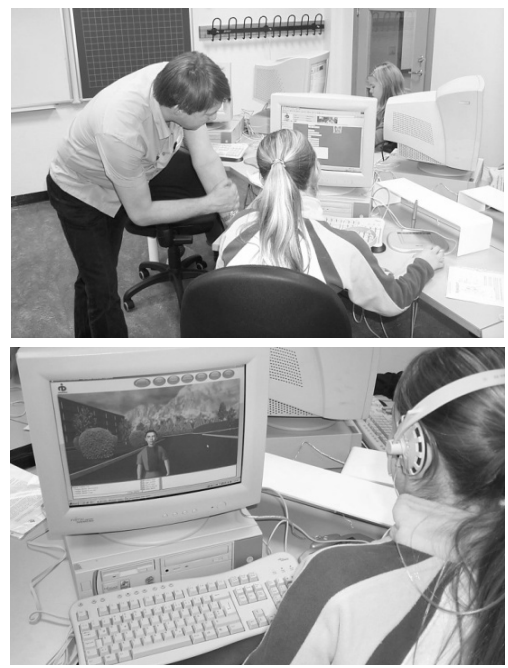

Figure 2. Students and their teacher at work, using the VRE in the classroom 


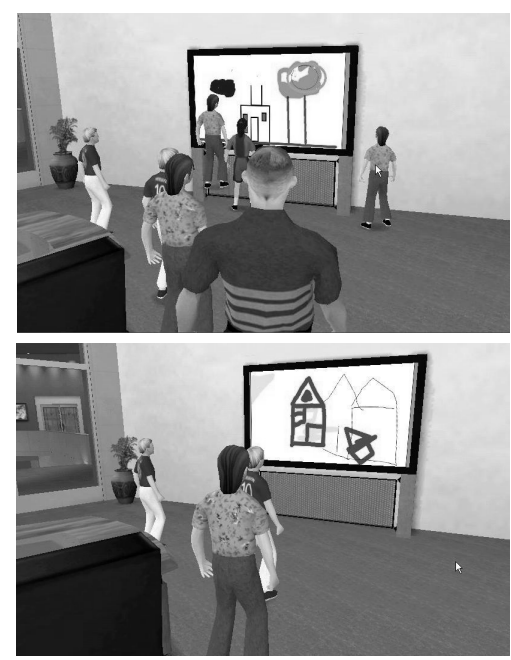

Figure 3. Students and their teacher at work inside the VRE

\section{Research Aims, Objectives and Questions}

The purpose of the pilot study was to gain an experience and understanding of the pedagogy of using VRE for cooperative idea generation within the school context.

The objectives were to:

1. Observe cooperative idea generation within the VRE;

2. Gain experience of using screen captured video data.

The research questions posed were:

1. How can a VRE be used for cooperative idea generation?

2. How do communications during the lesson support students' work?

3. How does cooperation relate to teaching and learning within these lessons?

\subsection{The pilot study lesson}

Four students, two boys and two girls from class seven, took part in the study; they were randomly selected from a group of interested students. A lesson plan was established by the participating teacher, who took responsibility for running the lesson, whilst the authors took care of data collection. The plan was based on:

1. Introduction and training in using the VRE

2. Brainstorming on a selected need, as determined by the students' own environment
3. Students developed solutions as a group within the VRE

The teacher explained the lesson plan to the students and also recorded the needs on the blackboard he had asked the students to find at home. The teacher then asked the students to work together in a group: he trained them to use the CAD application within the VRE. The students had to choose one need from the blackboard, brainstorm on it, and meet in the Virtual Reality to work on a solution together.

The group worked together on a joint drawing of their solution, then, finally, they saved the drawing to the VRE's database.

\subsection{Measuring instruments}

The pilot study was founded on an interpretive paradigm: the data was qualitative and the analysis based on grounded theory principles. This focused on understanding cooperative idea generation inside a Virtual Reality in a school context, and was done by describing and interpreting human communications, learning performance, and use of the VRE technology.

The data instruments were selected to enable triangulation and reliability; these were the teacher's and author's observations and screen captured videos. In order to analyse the data, the qualitative and inductive methodology, as developed by Glaser and Strauss (1967), was used. The specific instruments are listed against the research questions in the table below.

Table 1. Data collection methods used in the Pilot Study

Data Sources

a) The teacher's logbook

b) The researchers' observations

c) Screen captured videos

\subsection{Data collection and analysis}

The data collection methods used for the pilot study are shown in table 1 . Screen captured video was taken inside the VRE during the students' interaction, using the software Camtasia 3.0. The specific software Transana 
which analyses videos in qualitative research, was used to enable the data analysis. The video had no sound, only showing the text and graphics that the students communicated with: this was not an issue, as the students were not discussing during their work inside the VRE; rather, they were writing text to each other, which appeared on the screen.

The data was treated as follows:

1. Raw data collected and translated

2. Raw data summarised

3. Summaries analysed and classified into categories

4. Findings discussed and conclusions written for each data source

5. All the categories from the three data sources brought together and classified

6. Overall discussion written in the light of the literature and triangulation established

7. Conclusions drawn relating to the research questions

\subsection{Summary of data analysis}

The students decided to design a device to help them to wake up in the mornings during their summer vacation. This was done collectively, on the virtual whiteboard, for a period of 18 minutes. One of the students started to draw a simple bed (context); subsequently, others started to contribute until it was 'finished'.
The group solution drawing comprised of five main elements: a bed, a person, bedside unit, alarm clock and bucket, with all members contributing to the drawing. Most parts were two-dimensional representations, but the bed and the figure in the bed were threedimensional. The drawings (using a mouse) were not accurate, but reasonable for the age range: they showed a basic solution when together. In addition, the students drew grass, flowers, a cat's head, a mill, and a cloud with a text message inside. Finally, the students coloured and decorated the drawing and made it more detailed.

The main parts (figure 4 and the description below) were drawn in sequence. However, each part was visited more than one time by different students during the process, and, each time it was revisited, it got more detailed and sometimes coloured. Mostly, a single student was drawing each part, although more than one student sometimes drew different parts at the same time. On a few occasions, more than one student was drawing each part together.

There were four members (MS1, male student one; MS2, male student two; FS1, female student one and FS2, female student two. The process was the following:

1. MS1 began to draw the bed

2. MS2 began to draw the figure in the bed

3. FS3 began to draw the bedside unit

4. MS1 started to draw the bucket above the bed

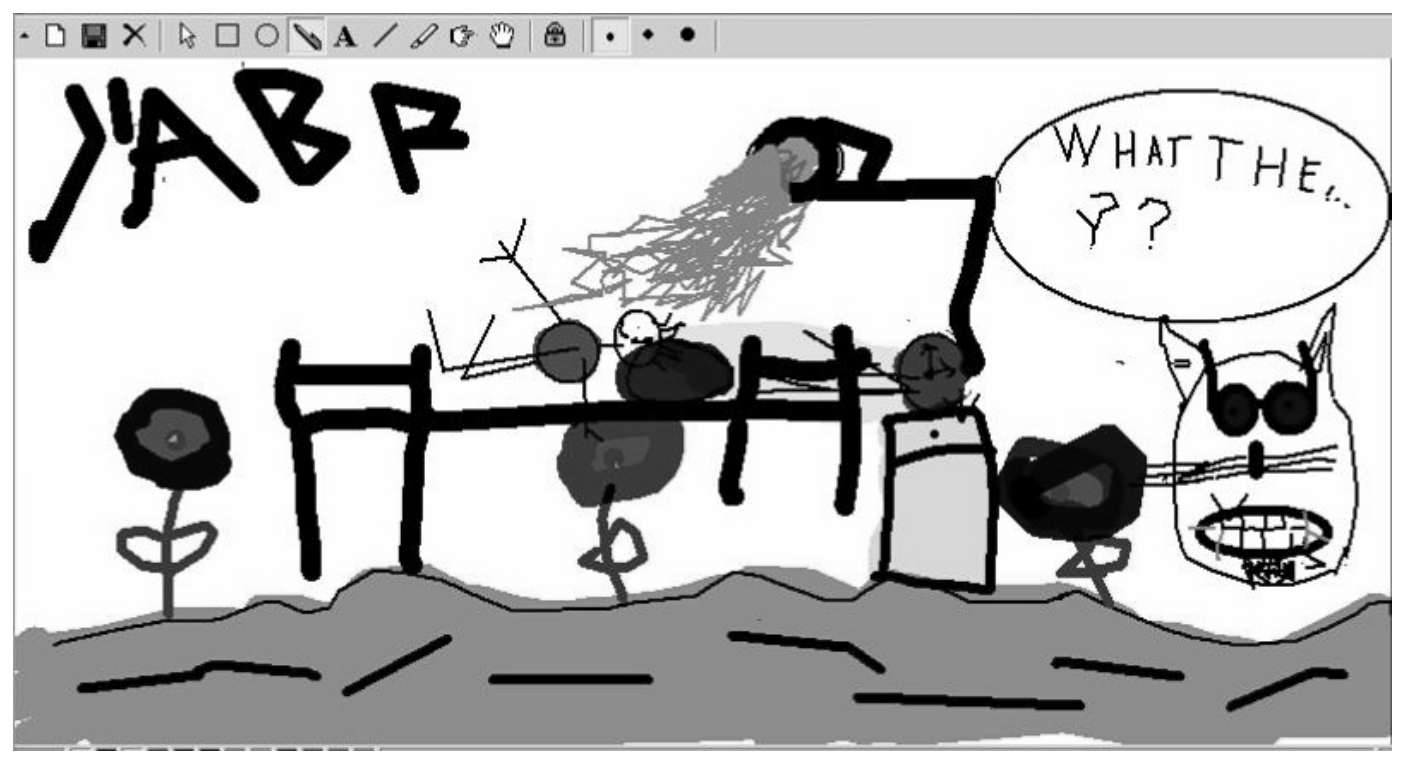

Figure 4. Shows the Students' Final Solution 
5. MS1 started to draw the alarm clock

6. FS3 drew the alarm clock hands

7. MS1 connected the alarm clock to the bucket

8. FS4 drew a face and hair on the figure in the bed

9. FS3 drew the cat's face with MS2

10. FS3 coloured the figure and the bed set

11. MS1 and FS3 continued with the cat face

12. FS3 drew glasses on the cat and male one connected the bucket further to the alarm clock and coloured the pillow

13. FS3 began and finished drawing the field and the grass

14. MS2 drew the cloud and the text inside

15. MS1 began to draw another cloud but later erased it. FS3 tried to write text inside

16. MS2 started to draw a game with male one.

17. FS3 drew the flowers; FS4 drew the black lines on the grass

18. MS1 drew the word Yeah (Jabb) as he won the game

Table 2 shows who started to draw different parts of the drawing (initiative): MS1 and FS3 were most active and clearly reacted with each other the most.

Table 2. Students' Initiatives

\begin{tabular}{|l|l|}
\hline Student & Initiatives \\
\hline Male one & 8 \\
\hline Male two & 3 \\
\hline Female three & 7 \\
\hline Female four & 1 \\
\hline
\end{tabular}

The students collaborated silently through their drawing and also wrote text to each other inside the VRE during the work. This appeared on each screen, so all were aware. Usually, a single student was drawing, but sometimes they worked in pairs or threes; only once was the whole group drawing together. The virtual whiteboard indicated who was drawing at any one time, enabling names and times to be related to activity

During their work, the students responded to each other and commented on the work with text messages within the VRE. These demonstrated a light hearted, collaborative spirit, including comments and emotional expressions such as "he he he he he", "lol", "how interesting", "beautiful" or "very pretty". Table 3 shows how often the students wrote these messages:

Table 3. Student Text Communication Rate

\begin{tabular}{|l|l|}
\hline Student & Frequency \\
\hline Male one & 7 \\
\hline Male two & 10 \\
\hline Female three & 15 \\
\hline Female four & 24 \\
\hline
\end{tabular}

Table 3 shows how male one only used text messaging seven times. MS1 communicated positively; for example, passing comment about the colours of the water and the flowers. MS2 also used text positively, expressing his opinion about the presentation of the drawings. He also mentioned how the size space used for specific parts of the drawings was an important issue. FS3's comments were more concerned with the design and presentation of the drawing, and MS1 had ideas and the initiative to start drawing; she, for example, started with the grass, flowers, and vivid light. She was clearly motivated and concerned about the presentation and the aesthetics of the drawing. FS4 was not communicating much about the design: her emphasis appeared to be for personal contacts in a humorous way, without focusing on the drawing. On some occasions she 'flirted' with male one, although she mostly communicated with MS1 and FS3.

Table 5 shows the collaborative activity when the students were drawing on the virtual whiteboard inside the VRE; It also shows cooperation frequency during the work and the time spent drawing, measured in seconds and minutes. The duration was found by creating time quotes with Transana (http://www. transana.org/download/index.htm) (taken from when each student started to draw and subsequently stopped). This illustrated the activities inside the VRE, and was used by the authors to highlight the cooperation. 
Table 5. Shows Student Activity when Collaborating inside the VRE. MS1 (1) is male one, MS2 (2) is male two, FS3 (3) is female three and FS4 (4) is female four.

\begin{tabular}{|c|c|c|c|}
\hline Student active & Seconds & Minutes & Frequency \\
\hline None & 391.3 & 6.5 & 45 \\
\hline MS1 alone & 204.4 & 3.4 & 22 \\
\hline MS2 alone & 258.4 & 4.3 & 23 \\
\hline FS3 alone & 206.5 & 3.4 & 18 \\
\hline FS4 alone & 24.4 & 0.4 & 5 \\
\hline MS1+ MS2 & 239.3 & 3.98 & 24 \\
\hline $\mathrm{MS} 1+\mathrm{FS} 3$ & 102.9 & 1.7 & 13 \\
\hline MS1+ FS4 & 72.1 & 1.2 & 7 \\
\hline MS2 + FS3 & 103.7 & 1.72 & 27 \\
\hline $\mathrm{MS} 2+\mathrm{FS} 4$ & 66.4 & 1.1 & 6 \\
\hline $\mathrm{FS} 3+\mathrm{FS} 4$ & 66.9 & 1.1 & 6 \\
\hline $\mathrm{MS} 1+\mathrm{MS} 2+\mathrm{FS} 3$ & 44.1 & 0.7 & 17 \\
\hline $\mathrm{MS} 1+\mathrm{MS} 2+\mathrm{FS} 4$ & 2.9 & 0.048 & 3 \\
\hline $\mathrm{MS} 2+\mathrm{FS} 3+\mathrm{FS} 4$ & 19.7 & 0.328 & 5 \\
\hline $\mathrm{MS} 1+\mathrm{FS} 3+\mathrm{FS} 4$ & 3.0 & 0.05 & 2 \\
\hline $\mathrm{MS} 1+\mathrm{MS} 2+\mathrm{FS} 3+\mathrm{FS} 4$ & 6.2 & 0.103 & 2 \\
\hline MS1 alone $+\mathrm{w}$. one student & 546.7 & 9.1 & 79 \\
\hline MS2 alone $+\mathrm{w}$. one student & 428.5 & 7.14 & 80 \\
\hline FS3 alone $+\mathrm{w}$. one student & 480.0 & 8 & 69 \\
\hline FS4 alone $+\mathrm{w}$. one student & 229.8 & 3.83 & 37 \\
\hline MS1 total time & 552.7 & 9.2 & 46 \\
\hline MS2 total time & 495.2 & 8.25 & 49 \\
\hline FS3 total time & 546.8 & 9.11 & 45 \\
\hline FS4 total time & 255.4 & 4.25 & 17 \\
\hline MS1 alone + w. two students & 540.1 & 9.0 & 44 \\
\hline MS2 alone + w. two students & 422.2 & 7.036 & 47 \\
\hline FS3 alone + w. two students & 483.8 & 0.83 & 42 \\
\hline FS4 alone + w. two students & 223.6 & 3.726 & 15 \\
\hline MS1with two students & 50.0 & 0.83 & 22 \\
\hline MS2 with two students & 47.0 & 0.78 & 25 \\
\hline FS3 with two students & 66.8 & 1.1 & 24 \\
\hline FM4 with two students & 25.6 & 0.42 & 10 \\
\hline MS1 with one student & 414.3 & 6.88 & 44 \\
\hline MS2i with one student & 409.4 & 6.8 & 40 \\
\hline FS3 with one student & 273.5 & 4.52 & 57 \\
\hline FM4 with one student & 205.4 & 3.4 & 19 \\
\hline One student drawing & 693.7 & 11.56 & 69 \\
\hline Two students drawing & 651.3 & 10.855 & 67 \\
\hline Three students drawing & 69.7 & 1.16 & 26 \\
\hline Four students drawing & 6.2 & 0.103 & 2 \\
\hline
\end{tabular}




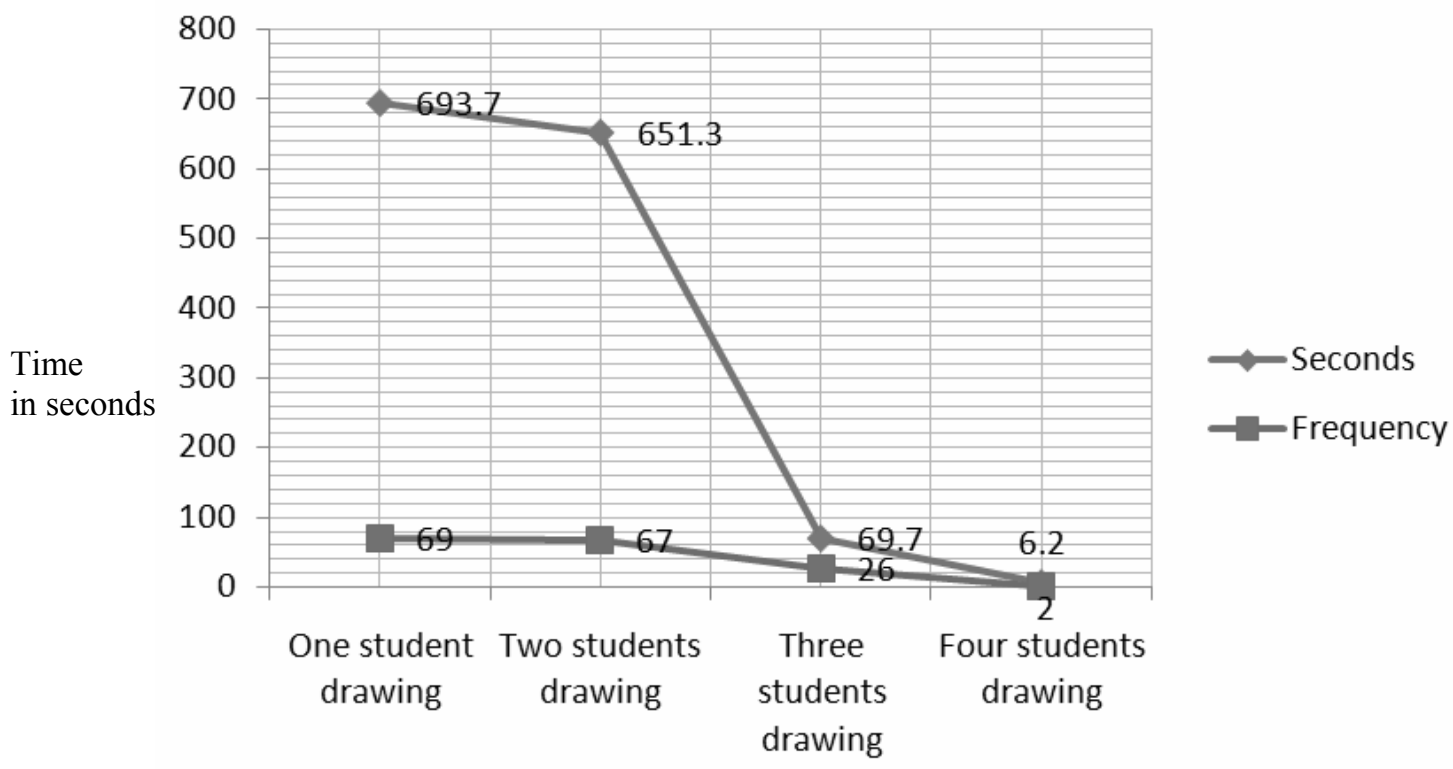

Figure 5. Shows how active the students were, whether they worked in ones, twos, threes or altogether. The blue line is the time they spent in total, whilst the red line shows how often they were active.

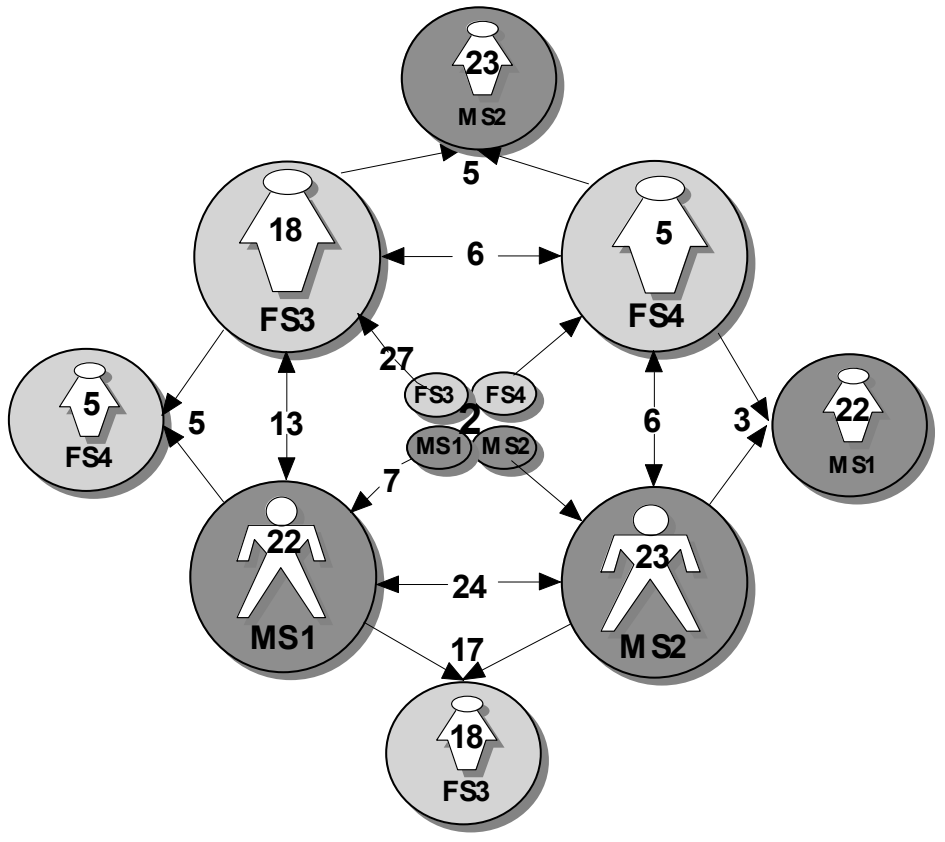

Figure 6. Shows how often the students worked alone and together, as groups of two, three or four; the blue colour indicates the males and the buff colour the females. On each figure is written the frequency when that individual worked alone. The arrows between the figures indicate cooperation with frequency, and the small central cluster indicates when all four collaborated, with 2 as the frequency.

The students mostly worked alone or in pairs on the virtual whiteboard (figure 5); MS1 spent more time than the others drawing. He started the work and was leader, along with FS3 (table 5). They started to draw the most important parts of the solution, such as the bed, the bedside cabinet, and the alarm clock. Also, MS1 and MS2 spent the most time together as a pair and were drawing the same parts together a few times. However, MS2 seldom began drawing new elements and collaborated mostly with MS1. MS2 was the most active alone.

MS1, MS2, and FS3 spent 3-4 minutes drawing, but FS4 spent just 0.4 minutes. The male students were more active in the 
technical part of the drawing, whereas the female students were more interested and active in the aesthetics part. MS2 had little initiative in drawing new parts (2), but did contribute to others' ideas; FS3 had the biggest initiative for decorating the drawing, and FS4 was passive when working alone but worked better in pairs and with three students. She spent most of her time together with FS3, and, subsequently, MS1, MS2 and FS3 spent the most time together.

\section{Discussion and Conclusion}

The teacher reported how the students were not discussing the work together face-to-face or online, during work inside the VRE; therefore, he concluded that the students were not collaborating together, but working as four individuals. However, by analysing the video and the interviews with the students, it was possible to see that the work was based on cooperation.

The drawing produced underlines the need for pre-training in the use of digital input devices for drawing: the students used the mouse, but lacked skill in using the CAD software. They may have been better it they had accepted the teacher's offer on training. However, the teacher gave informal training, included in the drawing test at the beginning of the lesson. The skill levels for individuals in using the VRE CAD were identified as significantly different. However they were all, with the exception of FS4, able to individually design inside the VRE and contribute to the solution. Student FS4 could contribute to other's designs.

During the exercise the students did not communicate face-to-face, but did use the VRE graphics and text facility. FS4 wrote most of the text messages that show, partly, her interest. However, most of the content of her messages were personal rather than relating to the work. Just two of the students were able to draw three-dimensionally, and, as before, the drawings differed in accuracy, clarity, and detail. Nevertheless, the students worked together and were able to submit a basic and understandable solution.

It should be noted that the students played different roles in their design work: their solution was drawn in 10 parts and in a logical order. It was MS1 who had the initiative to begin the drawing and he also designed most of the technical parts of the work; he used fewer text messages than the other students and was not asking for the others' opinions. FS3 showed initiative relating to colour and decorating the drawing, while MS1 and FS3 were the primary drivers for adding detail to the different parts as made by the other two.

Messages showed that the female students were primarily interested in the aesthetics of their drawing; this probably means that aesthetics are important for motivating female students and should therefore be included in the task (based on the two females within the group). This could also indicate different values between the sexes, as the female students were more interested in the visual aspects: this needs following up with far larger groups.

The students worked as avatars during the lesson, but never mentioned this fact: they were probably familiar with using avatars from playing inside of the VRE and also from playing other computer games at home. The students used the avatars to open the virtual whiteboard in the entire screen mode, and when they were not active they became avatars. They could use the VRE, with its avatars, as easily as other computer software. However, to enter the virtual whiteboard, the student had to move the avatar and this might have affected their performance and response speed.

To draw together as avatars was a relatively new experience for the students and therefore probably difficult for them. The students cooperated silently, but supported each other with text messages. Most often, students worked alone; the entire group rarely worked together or in threes. However, they did collaborate in pairs and spent a similar amount of time alone. They most often drew as individuals on different parts of the drawing, and drawing was also identified as a method for communicating during the design. FS4 was not very interested in the drawing, possibly because her skill was limited. The students seemed happy during the lesson: their text messages demonstrated a light-hearted collaborative spirit, including personal comments and emotional expressions. 


\section{Revisiting the Research Questions}

The aim of this pilot study was to gain an insight into the pedagogical tool of using VRE for cooperative idea generation within the school context. Cooperative idea generation activities within the VRE were observed.

Students silently communicated with each other by their drawings initiative and by writing text to each other. Pre-training students in drawing is important before they start using the VRE, as it allowing them to play together inside the VRE. An interesting teaching method used was to train students through gaming, before the lesson began; this made them familiar with the environment and the CAD. The students' skill levels were different, but everyone was able to contribute to the collaborative drawing activity. Students adopted different roles during their cooperation and they also showed different initiative, with one of the students leading the activity and two leading the idea generation. Students were interested in the aesthetic part of their drawing, and this affected their design in the end and generated a light spirit in the classroom that may well have enhanced idea generation. The avatars did not play a noticeable role in the pilot study; however, they may be useful in a game-based cooperative collaborative activity: this may represent an interesting continuity of this pilot study.

\section{REFERENCES}

1. BRICKEN, W., Learning in Virtual Reality. Human Interface Technology Laboratory, University of Washington, 1990.

2. *** Camtasia 3.0. Homepage for the software: http://www.camtasia.com (accessed 6. april 2009).

3. COHEN, E. G., Making Cooperative Learning Equitable, Educational Leadership, 56, 1998, pp. 18-22.

4. CROMBY, J., P. STANDEN, D. BROWN, Using Virtual Environments in Special Education. VR in the Schools, 1 (3), 1995, pp. 1-4.

5. CRUZ-NEIRA, C., D. J. SANDIN, T. A. DEFANTI, Surround-Screen Projection-
Based Virtual Reality: The Design and Implementation of the CAVE, ACM SIGGRAPH '93 Proceedings, Anaheim, CA, August 1993, pp. 135-142.

6. DEDE, C. J., The Future of Multimedia: Bridging to Virtual Worlds, Educational Technology; 32 (5), 1992, pp. 54-60.

7. DEMEREST, M., Understanding Knowledge Management, Journal of Long Range Planning 30 (3), 1997, pp. 374-384.

8. GUILFORD, J. P., Creativity. American Psychologist, 5(1), 1950, pp. 444-454.

9. GLASER, B., A. STRAUSS, The Discovery of Grounded Theory, Chicago: Aldine, 1967.

10. GOODWIN, M. W., Cooperative Learning and Social Skills: What Skills to Teach and How to Teach Them, Interventions in School \& Clinic, 35, 1999, pp. 29-34.

11. HAMIT, F., Virtual Reality and the Exploration of Cyberspace, Carmel, Indiana: Sams Publishing, 1993.

12. JOHNSON, D., J. JOHNSON, Cooperative Learning. 2001, Retrieved on November 15, 2002 from the web site: http://www.clcrc.com/pages/ cl.html.

13. JOHNSON, D. W., R. T. JOHNSON, M. B. STANNE, Cooperative Learning Methods: A meta-analysis. Retrieved July, 2000 from the World Wide Web: http://www.clcrc.com/pages/clmethods.html

14. JOHNSON, G. M., Principles of Instruction for At-risk Learners, Preventing School Failure, 42, 1998, pp. 167-181.

15. JOHNSON, D. W., R. T. JOHNSON, M. B. STANNE, Cooperative Learning Methods: A Meta-analysis. Retrieved July, 2000 from the World Wide Web: http://www.clcrc.com/pages/clmethods.html

16. JOYCE, W. B., On the Free-rider Problem in Cooperative Learning, 
Journal of Education for Business, 74, 1999, pp. 271-274.

17. KAGAN, S., Cooperative Learning. San Clemente, California: Kagan Publishing, 1994.

18. KAGAN, S., Group Grades Miss the Mark, Educational Leadership, 52, 1995, pp. 68-72.

19. KRUEGER, M., Artificial Reality II. Reading, MA: Addison-Wesley, 1991.

20. LANIER, J., M. MINSKY, S. FISHER, A. DRUIN, Virtual Environments And Interactivity: Windows To The Future, 1989 ACM Siggraph Panel Proc., 1991.

21. LOEFFLER, C. E., T. ANDERSON, (Eds.), The Virtual Reality Casebook. New York, Van Nostrand Reinhold, 1994.

22. MAIER, N. R. F., Problem-solving Discussions and Conferences: Leadership Methods and Skills. New York: McGraw-Hill, 1963.

23. MILLER, W. L., L. MORRIS, Fourth Generation R\&D: Managing Knowledge, Technology and Innovation. John Wiley \& Sons, Inc. New York, 1999, p. 347.

24. MCINNERNEY, J. M., Collaborative or Cooperative Learning? Online Collaborative Learning: Theory and Practice Information Science Publishing. USA, 2002, pp. 218-229.

25. MILLIS, B., Cooperative Learning. 1996, May, Paper presented at The University of Tennessee at Chattanooga Instructional Excellence Retreat, USA. Retrieved on February 25, 2002 from the web site: http://www.utc.edu/ TeachingResource-Center/CoopLear.html.

26. OSBORNE, A. F., Applied Imagination: Principles and Procedures of Creative Problem Solving, New York, Scribner's, 1963.

27. PAGE, T., G. THORSTEINSSON, M. LEHTONEN, A. NICULESCU, Management of Knowledge in a Problem Based Learning Environment, Studies in Informatics and Control, 18(3), September 2009, ISSN 1220-1766, pp 255-262.
28. PAGE, T., G. THORSTEINSSON, A. NICULESCU, A Pedagogical Consideration of Technology Enhanced Laboratory Work in Technology Education, Studies in Informatics and Control, 17(1), March 2008, ISSN 1220-1766, pp 85-94.

29. PANTELIDIS, V. S., North Carolina Competency-based Curriculum Objectives and Virtual Reality. Unpublished document. Greenville, NC: Virtual Reality and Education Laboratory, School of Education, East Carolina University, 1993.

30. PAULSEN, M. F., Online Education and Learning Management Systems. Oslo, NKI Forlaget, 2003.

31. RAVITCH, D., Edspeak: a Glossary of Education Terms, Phrases, Buzzwords, and Jargon. Alexandria, Va.: Association for Supervision and Curriculum Development, 2007.

32. SANTANEN, E. L., O. R. BRIGGS, L. ROBERT, G. JAN DE VREEDE, Causal Relationships in Creative Problem Solving: Comparing Facilitation Interventions for Ideation, Journal of Management Information Systems. Armonk: (20:4), 2004, p. 167.

33. SCHWIENHORST, K., Co-constructing Learning Environments and Learner Identities - Language Learning in Virtual Reality, Proc. ED-Media/EDTelecom, Freiburg, 1998.

34. SLAVIN, R. E., Synthesis of research on cooperative learning, Educational Leadership, 48, 1991, pp. 71-82.

35. SLAVIN, R. E., Cooperative Learning, Boston, Allyn and Bacon, 1995.

36. SLAVIN, R. E., N. L. KARWEIT, N. A. MADDEN, Effective Programs for Students At Risk, Boston, Allyn and Bacon, 1989.

37. SMITH, F. G., Towards a Logic of Innovation. The International Handbook on Innovation, Elsevier Science Ltd., 2001.

38. $* * *$ The Oxford English Dictionary 2009. Accessed via http://www.oed.com/ (6 April 2009). 
39. THORSTEINSSON, G., Innovation and Practical Use of Knowledge, Data International Research Conference 2002, bls. 171-177.

40. THORSTEINSSON, G., H. G. DENTON, Ideation in a Virtual Learning Environment: A Pilot Project from Iceland in Innovation Education, The Design and Technology Association International Research Conference 2006, Norman, E.W.L., Spendlove, D. and Owen-Jackson, G. (eds), DATA, The Design and Technology Association International Research Conference 2006, Telford, July 2006, ISBN 189878880 4, pp 155-164.

41. THORSTEINSSON, G., H. DENTON, Developing an Understanding of the Pedagogy of Using a Virtual Reality Learning Environment (VRLE) to support Innovation Education (IE) in Iceland: a Literature Survey. Design and Technology Education: An International Journal, 13(2), 2008, ISBN 1360-1431, pp 15-26.
42. THORSTEINSSON, G., M. LEHTONEN, T. PAGE, H. RUOKAMO, A Virtual Learning Environment for the Support of Teaching, Studying and Learning in Technology Education (Winner of best paper prize), Proc. of the 4th IASTED Int. Conf. on Web-based Education, (Ed) V. Uskov, WBE 2005, Grindelwald, Switzerland, ACTA Press. February 2005, pp. 109-118.

43. *** Transana. The software's homepage: http://www.transana.org/download/index. htm (accessed 6.april 2009).

44. *** The Webster Dictionary: http://www.webster.com. (Accessed 6 April 2009).

45. ZELTZER, D., Autonomy, Interaction and Presence, Presence, 1, 1992, pp. 127-132.

46. WINN W., A Conceptual Basis for Educational Applications of Virtual Reality, Washington Technology Centre, University of Washington, 1993. 